\title{
Social Support
}

\author{
Jorunn Drageset
}

\section{Abstract}

Social support by our social network proves to be important for our health. The opposite of good social support is loneliness. First and foremost, it seems that social support includes emotional support, belonging in a social community, being valued, practical help, and information and guidance. Social support represents a vital salutogenic resource for individuals' mental health.

This chapter explains the concept of social support in relation with other concepts of specific relevance, such as coping and quality of life. In a health-promoting perspective, this chapter presents the concept of social support and its theoretical basis. A brief description of questionnaires assessing social support is provided, as well as a brief summary of evidence demonstrating the salutogenic potential of social support, both as a preventive and a health-promoting resource.
J. Drageset $(\bowtie)$

Western Norway of Applied Sciences, Bergen, Norge

University of Bergen, Bergen, Norway

e-mail: jorunn.drageset@hvl.no,

jorunn.drageset@uib.no

\section{Keywords}

Social support $\cdot$ Social relationships $\cdot$ Health promotion $\cdot$ Sense of coherence $\cdot$ Older people $\cdot$ Social networks

\subsection{Introduction}

The concept of social support is multidimensional and can be incorporated into a larger context termed social capital, where social support and social networks are parts [1]. Social support and social networks are described in different ways; mainly these can be presented as (1) structurally and functionally and (2) formally and informally [2]. Nursing care can, for example, be a formal support to people who have no close friends.

The structural aspect of social support refers to the existence and size of a social network, and the extent to which the person is connected within a social network, like the number of social ties (quantity of the relationships) and the characteristics of the social exchanges between individuals (e.g., social support activities, frequency of interactions). Relationships with family, friends, and members in organizations might contribute to social integration [2, 3]. The functionally/qualitative aspect of social support refers to a person's appraisals of the social support he or she experience, or how integrated a person is within his or 
her social network; that is, the quality or depth of the relationships $[2,3]$. Furthermore, the specific functions that members in a social network can provide such as emotional (i.e., reassurance of worth, empathy, affection), instrumental (i.e., material aid), and informational (i.e., advice, guidance, feedback) $[2,4,5]$ are also vital aspects of social support. Thus, social support refers to the cognitive/functional qualitative aspects of human relationships, such as the content and availability of relationships with significant others, whereas social network refers to the quantitative and structural aspects of these relationships [2, 5].

Social support occurs in the presence of a social network $[2,6]$; the concept is often used in a broad sense, referring to any process through which social relationships might provide health and well-being [2, 7]. Reviewing the literature reveals that social support is understood from a subjective viewpoint, including emotional support, esteem support, social integration or network support, provision of information and feedback and tangible assistance [2, 4, 5]. Measures that reflect each dimension of social support are therefore needed [4].

Researchers have commonly made a distinction between perceived and received support [2, $3,8]$. Perceived support refers to a person's subjective judgment that will give help or have given help during times of need. Received support refers to specific support (e.g., advice) that is given if needed, actually provided to the person $[2,5,8]$. The different, specific types of social support that an individual may experience include emotional support (listening support, comfort, and security), informational support (advice and guidance), esteem support (increasing the person's sense of competence), and tangible support (concrete assistance such as providing transportation or financial assistance). These different, specific types of social support have shown different correlations with health and personal relationships; only perceived support is consistently linked to better mental health, whereas received support and social integration are not found to relate with health [9]. Accordingly, there is an agreement in the literature that the only aspect of social support that is linked to health outcomes is perceived support, or the belief that help is avail- able if needed, rather than the help and support that is actually received $[2,5,8,9]$.

Based on the relationships between social support, stressful life events, and physical and mental health, the literature of social support proposes two models: (1) "buffering support" and (2) "main support" [2, 10-12]. The first model reflects the fact that social support is beneficial only under conditions of high stress, that is, the buffering effect. This means that individuals with a high level of perceived social support will have fewer negative health effects following stressful events than those with a low level of perceived social support. The second model states that social support is beneficial regardless of an individual's level of life stress and predicts positive influences of social support on physical and mental health, independently of the presence and the absence of stressful events [2, 10-12].

In his salutogenic theory of health, Antonovsky [13] introduced the concept of "sense of coherence" (SOC) as a global life orientation of viewing the world and one's environment as comprehensible, manageable, and meaningful. Antonovsky (1987) claimed that the way people view their life influences on their health. These three elements, comprehensibility, manageability, and meaningfulness, formed the concept of SOC. Another salutogenic concept is general resistance resources (GRR), involving aspects such as knowledge, intelligence, coping strategy, and social support. The GRRs are characterized by consistency, participation in shaping one's outcome, and a balance between underload and overload. These resistance resources are shaped by life experiences and reinforce the SOC. Social support is a GRR that builds up a strong SOC which in turn has proven to have a buffering and key effect on health [12].

\subsection{Theoretical Approaches to the Concept of Social Support}

\subsubsection{Social Capital}

Putnam, Leonardi, and Nanetti [14] make a distinction between two kinds of social capital: bonding capital and bridging capital. Bonding 
capital occurs when you are socializing with people who are alike you: same age, same religion, and so on (interconnecting dimensions). Bridging is what you do when you make friends with people who are not like you (e.g., between generations). These two kinds of social capital, bonding and bridging, do strengthen each other.

Coleman [15] describes social capital as a support that facilitates an individual's or a collective's action generated by networks of relationships through reciprocity, trust, and social norms, depending entirely on the individuals. That means that an individual can use these embedded resources whenever needed. Social capital is thereby inherent in the structure of relations between individuals $[1,15]$.

\subsubsection{Social Relationships and Social Provisions Theory}

Weiss's [16] theory of social relationships incorporates six major elements/provisions of the most current conceptualizations of social support which are (1) attachment, (2) social integration, (3) opportunity for nurturance, (4) reassurance of worth, (5) guidance, and (6) reliable alliance proposed by theorists in this area. Hence, Weiss theory compares the six social provisions with the dimensions of social support that have been described by other authors $[4,5,17]$. The theory of social relationships by Weiss focuses on the person's need to interact with others. The theory differentiates between primary and secondary relationships. The former comprises close, warm, and frequent relationships and is obtained from family and friends. The latter includes working relationships of less emotional importance than the primary ones, although it has great influence [16, 18]. Weiss [16] describes six different social relationships/provisions that must be obtained through relationships with other people, and all provisions are needed for an individual to feel adequate support. Each of the six provisions is usually obtained from a specific kind of relationship, but several may be obtained from the same person. Different provisions may be critical at different stages of the life cycle.

Weiss' concept of social provisions includes the functioning of social networks; that certain types of relationships usually provide each of the social provisions (attachment, social integration, opportunity for nurturance, reassurance of worth, guidance, and reliable alliance). Deficits in the specific provisions might lead to loneliness, boredom, low self-esteem, and anxiety. As older people experience changes in close relationships, failing health, or death of a spouse or friends, Weiss' concept of social provisions appears to be appropriate for understanding the relationships between social interaction and psychological wellbeing among older adults [19]. To the extent that deficits in social provisions affect health, social support may affect health-related quality of life directly through the dimensions of emotional support, network support, and esteem support. The six provisions are described as follows:

1. Attachment

(a sense of emotional closeness and security often provided by a spouse or romantic partner).

2. Social integration

(a sense of belonging to a group that shares common interests and activity, often provided by friends).

3. Opportunity for nurturance

(a sense of responsibility for the well-being of another person, often obtained from children).

4. Reassurance of worth

(acknowledgement of one's competence and skill, usually obtain from co-workers).

5. Guidance

(advice and information, usually obtained from teachers, mentors and parents).

6. Reliable alliance (the assurance that one can count on people for assistance under any circumstances, usually obtained from close family member).

\subsection{The Measurement of Social Support}

So far, this chapter has shown that social support is important for both mental and physical health. Therefore, regardless of illness and age, the evaluation of social support is often part of interview 
surveys about health in the general population and among patients. The questionnaires assessing social support cover subjective experiences of social support. The Social Support Scale (OSS-3) (WHO Regional Office for Europe: EUROHIS, 2003) is a three-question form commonly used in the general population. This scale contains questions about "number of close people," "interest from others," and "help from neighbors." The responses are grouped into weak, medium, and good social support according to the scores on each of the three questions in the OSS-3 [20].

Another form is the Social Provisions Scale (SPS) which is often used in clinical settings, across diagnosis and ages [4]. This form builds on Weiss' theory of social relationships and the six provisions of social support (reliable alliance, guidance, affiliation, social integration, selfesteem affirmation, and the opportunity to mean something to others/provide care). This scale has 24 questions, four for each of the six subdimensions. The 24 questions are presented in the form of statements rated from "Strongly Disagree," "Disagree," "Agree," and "Strongly Agree." The SPS also exists in a shorter version including 16 questions covering "affiliation," "social integration," "affirmation of self-worth," and "opportunity to mean something to others/care." This 16-item short version is most often used among older people. The16-item version scale has proven to be a valid and reliable instrument when used among older people living in the community [21, $22]$ and in nursing homes [22, 23].

\subsection{Social Support and Health Promotion}

Social support has proven to be health promoting by strengthening individual's coping abilities, health, and quality of life while facing stress; these associations have been seen in many different populations of both healthy and sick people $[13,24,25]$. The salutogenic nursing approach focuses on identifying the individual's health resources and actions to promote the person's health processes toward the positive side of the disease/ease-continuum [13].
Antonovsky introduced the salutogenic concept Sense of Coherence (SOC) [13, 24]. The salutogenic health theory was founded on the basic idea of what creates health; the concepts of SOC and generalized resistance resources (GRRs) represent the central ideas of Antonovsky's salutogenesis [13, 24]. These concepts harmonize well with the philosophy of the Ottawa Charter in 1986 [25, 26] stating health as a process enabling people to develop health through their assets and thus having the opportunity to lead a good life. The way people view the world affects their ability to manage tension and stress. The outcome (health) depends on perceived SOC and the GRRs available, i.e., material, ego identity, and social support [27]. The SOC consists of three dimensions: comprehensibility, manageability, and meaningfulness, reflecting the interaction between the individual and the environment. Evidence shows that SOC is strongly associated with perceived health, especially mental health $[12,27]$. Furthermore, SOC has demonstrated a main, moderating, or mediating role in the explanation and prediction of health among adult in Swedish and Finnish population $[12,27]$.

Social support is a vital generalized resistance resource and thereby seen as a salutogenic concept [28]. Close supportive relations is according to Antonovsky [13], a prerequisite for developing a strong SOC. The importance of the different aspects of supportive relations or dimensions of social support can vary among different populations. A systematic review showed that social support from spouse, friends, and health professionals was an important factor in establishing and maintaining healthy habits for nutrition and lifestyle in people diagnosed with diabetes [29]. Social support from close friends has also shown a positive effect on mental health problems in older people (aged 65 years or older) and is described as a "buffer" between mental disorders and physical impairments such as hearing impairment. In the same study, social support was significant independently associated with psychological distress [30]. Wang, Mann, LloydEvans, Ma, and Johnson [31] found substantial evidence from prospective studies that people 
with depression who perceive their social support as poorer have worse outcomes in terms of depressive symptoms, recovery, and social functioning. Further, studies show that social support perceived as emotional support, and reassurance of one's worth, is important for quality of life and loneliness among older nursing home patients with and without cancer as well as in homedwelling older adults [23, 32, 33]. Kvale and Synnes [34] found that, by providing good care, health care personnel performed to be a vital resource strengthening cancer patients' general resistance resources in a stressful life situation. Nurses, doctors, family, and friends functioned as vital resources at these individuals' disposal when needed; thus, nursing care can be a specific resistance resource buffering stress [34]. The studies listed above signify the significance of having one special person in one's life to be confident in and feel appreciated by. This special relationship involves being listened to so that the person feels understood, seen, accepted, acknowledged, and confirmed. This kind of emotional support creates a sense of security and well-being and thus acts as a health promotion resource.

Social support and the quantity of close relationships are of great importance for mortality risk. A group of older adults $(N=2.347)$ who were examined about close friends/family, marital status, and mortality three times over 10 years disclosed that widowed older adults who had fewer than 4-6 close relationships had a significantly increased risk of death 10 years later compared to their married counterparts [35]. Clearly, the social relationships serve a critical role in overall health and well-being.

Furthermore, research shows that social support is important for the burden of care among older people giving care to a partner with dementia. A cross-sectional observation study of 97 individuals, $\geq 65$ years old living with a partner having symptoms of dementia, showed that lower level of burden of care was significantly related with higher level of attachment and higher level of SOC [36]. Similarly, the findings from a study of cognitively intact nursing home residents (mean age 85 years) showed a strong positive correlation of nurse-patient interaction with anx- iety, depression, hope, meaning, and selftranscendence [37-40]. These studies indicate that the relational qualities embedded in the nurse-patient interaction have a health-promoting influence.

Lämås and colleagues [41] conducted a crosssectional study of 136 participants (mean 82 years) showing that participation in social relations and the experience of self-determination in activities in and around the house are significantly associated with thriving. Moreover, the experience of social support has been found to be health-promoting among people 75 years or older living at home; the frequency of home nursing was important for health promotion [21]. People with higher education who experienced good social support reported less need for home care than those who did not experience good support [21]. This indicate that besides higher education, support from social network is health promotion.

In summary, based on this literature review, social support has shown to significantly impact on psychological distress, quality of life, loneliness, burden of care, as well as anxiety, depression, hope, meaning, self-transcendence, and mortality risk. Social support has also shown to be a "buffer" between mental disorders and physical impairments. Thus, based on the existing evidence, social support shows to act as a vital health promotion resource representing a salutogenic concept.

\subsection{How Can the Health Service Contribute to Social Support of Older Persons and Relatives?}

\subsubsection{Clinical Implications}

The quality of social support from family and friends as well from caregivers is a vital resource in health promotion for older people. Consequently, knowledge about social support is important for health care workers providing care and treatment in all ages. This knowledge should be included in different health educations as well as to health care leaders. 
Quality of care for the elderly requires good competence and knowledge of the importance of psychosocial care for health and well-being. Attention should be made to the importance of facilitating the opportunity to maintain contact with family (i.e., spouse, children) and close friends. Emotional support from significant others has proven to be important for health and well-being, embodying a salutogenic health resource. Health care professionals should facilitate, safeguard, or improve social support and, if necessary, provide social support. The starting point must be based on each person's needs, ensuring that the patient's autonomy and integrity are respected.

The different, specific types of social support (attachment, social integration, opportunity for nurturance, reassurance of worth, guidance, and reliable alliance) have certain types of relationships that are usually provided to each of the social provisions.

Appropriate strategies to ensure emotional support (the need for love and friendship) can be to ask the person if he/she has one or more confidants and then facilitate social contact based on the needs and wishes. Spend time and meeting the patient where he/she is based on the care needs. The emotional support creates a sense of security and well-being and thus acts as a health promotion resource. To ensure network support (need for affiliation) could be to facilitate social contact with friends and significant others, with patients and other residents (for those living in nursing homes), and motivate the patient to take the initiative and participate in social contexts. Further, being valued (support when it comes to self-esteem), nursing care personnel should be aware of the importance to help and support the person's self-esteem in their daily contact, i.e., the care should be based on the people's needs and not on what care personnel believe they need, because the person's autonomy and integrity should be respected.

Concrete support (practical help) could be done by identifying the person's previous strengths and the internal and external resources that are currently available and helping and moti- vating the person to use these available resources despite any limitations.

Regarding instrumental support (information and guidance), professionals should provide health care information to the person in a way that is easy for them to understand.

The evidence shows both a "main" and "buffer" effect of social support as important healthpromoting resource in maintaining health and well-being. What type of support that has "main" or "buffering" effect can vary among situations and different persons and population. The most important is that the only aspect of social support that is linked to health outcomes is perceived support, or the belief that help is available if needed, rather than the help and support that is received.

\subsection{Conclusion}

Social support involves that you experience security and closeness, can have the opportunity to care for others, that you belong to a social network, feel respected and valued, and participate in a community with mutual obligations. The opposite of social support is loneliness. Our social network has an impact on our health. First and foremost, it seems that social support includes emotional support, belonging in a social community, being valued, practical help and information, and guidance which are the healthpromoting factors.

\section{Take Home Messages}

- The concept of social support is multidimensional and can be incorporated into larger context termed social capital, where social support and social networks are parts.

- Social support can be categorized and measured in several different ways, where emotional support, belonging in a social community, being valued, practical help, and information and guidance are the common functions.

- According to the salutogenic health theory, social support is a general resistant resource which can influence on people's sense of coherence. 
- Social support is a predictor of physical and mental health, and a buffer that protects (or "buffers") people from the bad effects of stressful life events (e.g., death of a spouse, relocation).

- Positive associations between social support and individual's coping abilities, health and quality of life while facing stress, have been found in many different populations of both healthy and sick people.

- Social support has shown to significantly impact on psychological distress, quality of life, loneliness, burden of care, as well as anxiety, depression, hope, meaning, selftranscendence, and mortality risk.

\section{References}

1. Rostila M. The facets of social capital. J Theory Soc Behav. 2011;41(3):308-26.

2. Kent de Grey R, Uchino B, Trettevik R, Cronan S, Hogan J. Social support. Oxford Bibliogr Pscychol. 2018.

3. Taylor SE. Social support: a review. In: IMSF, editor. The handbook of health psychology. New York: Oxford University Press; 2011. p. 189-214.

4. Cutrona CE, Russel DW. The provisions of social relationships and adaptation to stress. In: Jones WH, Perlman D, editors. Advances in personal relationships a research annual I. Greenwich, CT: Jai Press; 1987. p. 37-67.

5. Sarason BR, Sarason IG, Pierce GR. Social support: an interactional view. A Wiley-interscience publication. Hoboken, NJ: Wiley; 1990.

6. Langford CP, Bowsher J, Maloney JP, Lillis PP. Social support: a conceptual analysis. J Adv Nurs. 1997;25(1):95-100.

7. Cohen S, Lynn U, Gottlieb B. Social support measurement and intervention: a guide for health and social scientists. Oxford: Oxford University Press; 2000.

8. Beauchamp M, Eys M. Coping, social support, and emotion regulation in teams. In: Eys MRBMA, editor. Group dynamics in exercise and sport psychology: contemporary themes. London: Routledge; 2014. p. 222-39.

9. Uchino BN. Understanding the links between social support and physical health: a life-span perspective with emphasis on the Separability of perceived and received support. Perspect Psychol Sci. 2009;4(3):236-55.

10. Cutrona C, Russell D, Rose J. Social support and adaptation to stress by the elderly. Psychol Aging. 1987;1(1):47-54.
11. Cohen S. Social relationships and health. Am Psychol. 2004;59(8):676-84.

12. Eriksson M, Lindstrom B. Antonovsky's sense of coherence scale and the relation with health: a systematic review. J Epidemiol Community Health. 2006;60(5):376-81.

13. Antonovsky A. Unraveling the mystery of health: how people manage stress and stay well. San Fransisco: Jossey-Bass; 1987.

14. Putnam RD, Leonardi R, Nanetti RY. Making democracy work: civic traditions in modern Italy. Princeton, NJ: Princeton University Press; 1994.

15. Coleman JS. Social capital in the creation of human capital. In: Networks in the knowledge economy; 2003. p. 57-81.

16. Weiss RS. The provisions of social relationships. In: Rubin Z, editor. Doing unto others. Englewood Cliffs, NJ: Prentice Hall; 1974. p. 17-26.

17. Cohen S, Syme SLE. Social support and health. New York: Academic Press; 1985.

18. Weiss RS. Loneliness. The experience of emotional and social isolation. Cambridge, MA: The Massachusetts Institute of Technology; 1973.

19. Mancini JA, Blieszner R. Social provisions in adulthood: concept and measurement in close relationships. J Gerontol. 1992;47(1):P14-20.

20. Abiola T, Udofia O, Zakari M. Psychometric properties of the 3-item Oslo social support scale among clinical students of Bayero university Kano. Niger Malay J Psychiatry. 2013;22(2):32-41.

21. Saevareid HI, Thygesen E, Lindstrom TC, Nygaard HA. Association between self-reported care needs and the allocation of care in Norwegian home nursing care recipients. Int J Older People Nurs. 2012;7(1):20-8.

22. Bondevik M, Skogstad A. Loneliness among the oldest old, a comparison between residents living in nursing homes and residents living in the community. Int $\mathrm{J}$ Aging Hum Dev. 1996;43(3):181-97.

23. Drageset J, Kirkevold M, Espehaug B. Loneliness and social support among nursing home residents without cognitive impairment: a questionnaire survey. Int $\mathbf{J}$ Nurs Stud. 2010;48(5):611-9.

24. Antonovsky A. Health, stress and coping: new perspective on mental and physical well-being. San Fransisco: Jossey-Bass; 1979.

25. Eriksson M, Lindstrom B. A salutogenic interpretation of the Ottawa charter. Health Promot Int. 2008;23(2):190-9.

26. World Health Organization, WHO. Ottawa charter for health promotion: an international conference on health promotion, the move towards a new public health. Ottawa, Geneva: WHO; 1986a.

27. Eriksson M, Lindstrom B. Antonovsky's sense of coherence scale and its relation with quality of life: a systematic review. J Epidemiol Community Health. 2007;61(11):938-44.

28. Eriksson M. Unravelling the mystery of Salutogenesis. The evidence base of the salutogenic research as measured by Antonovsky's sense of coherence scale; 2007. 
29. Mohebi S, Sharifirad G, Feizi A, Botlani S, Hozori M, Azadbakht L. Can health promotion model constructs predict nutritional behavior among diabetic patients? J Res Med Sci. 2013;18(4):346-59.

30. Boen H, Dalgard OS, Bjertness E. The importance of social support in the associations between psychological distress and somatic health problems and socioeconomic factors among older adults living at home: a cross sectional study. BMC Geriatr. 2012;12:27.

31. Wang J, Mann F, Lloyd-Evans B, Ma R, Johnson S. Associations between loneliness and perceived social support and outcomes of mental health problems: a systematic review. BMC Psychiatry. 2018;18(1):156.

32. Elovainio M, Kivimake M. Sense of coherence and social support-resources for subjective well-being and health of the aged in Finland. Int J Soc Welfare. 2000;9:128-35.

33. Drageset J, Eide GE, Dysvik E, Furnes B, Hauge S. Loneliness, loss, and social support among cognitively intact older people with cancer, living in nursing homes--a mixed-methods study. Clin Interv Aging. 2015;10:1529-36.

34. Kvale K, Synnes O. Understanding cancer patients' reflections on good nursing care in light of Antonovsky's theory. Eur J Oncol Nurs. 2013;17(6):814-9.

35. Manvelian A, Sbarra DA. Marital status, close relationships, and all-cause mortality: results from a 10-year study of nationally representative older adults. Psychosom Med. 2020;82:384.

36. Stensletten K, Bruvik F, Espehaug B, Drageset J. Burden of care, social support, and sense of coherence in elderly caregivers living with individuals with symptoms of dementia. Dementia. 2016;15(6):1422-35.

37. Haugan G. The relationship between nursepatient interaction and meaning-in-life in cognitively intact nursing home patients. J Adv Nurs. 2014;70(1):107-20.

38. Haugan G. Nurse-patient interaction is a resource for hope, meaning in life and selftranscendence in nursing home patients. Scand J Caring Sci. 2014;28(1):74-88.

39. Haugan G, Moksnes UK, Lohre A. Intrapersonal self-transcendence, meaning-in-life and nurse-patient interaction: powerful assets for quality of life in cognitively intact nursing home patients. Scand J Caring Sci. 2016;30:790.

40. Haugan G, Innstrand ST, Moksnes UK. The effect of nurse-patient interaction on anxiety and depression in cognitively intact nursing home patients. J Clin Nurs. 2013;22(15-16):2192-205.

41. Lamas K, Bolenius K, Sandman PO, Bergland A, Lindkvist M, Edvardsson D. Thriving among older people living at home with home care services-a cross-sectional study. J Adv Nurs. 2020;76(4):999-1008.

Open Access This chapter is licensed under the terms of the Creative Commons Attribution 4.0 International License (http://creativecommons.org/licenses/by/4.0/), which permits use, sharing, adaptation, distribution and reproduction in any medium or format, as long as you give appropriate credit to the original author(s) and the source, provide a link to the Creative Commons license and indicate if changes were made.

The images or other third party material in this chapter are included in the chapter's Creative Commons license, unless indicated otherwise in a credit line to the material. If material is not included in the chapter's Creative Commons license and your intended use is not permitted by statutory regulation or exceeds the permitted use, you will need to obtain permission directly from the copyright holder. 